all a book of criticism, a work of polemic and struggle; it is at the same time a pedagogical work, and a philosophical work. . .'? Why does he write of Galileo's allegedly "Platonic" hypothesis of the planets all being accelerated into their orbits by falling from a unique point in space that "the correspondence is amazingly close"'? (It is not, as Newton pointed out long ago in his second letter to Richard Bentley, though Galileo seems to accept it as true.) Why is it profitable or illuminating to treat Galileo's Dialogue in case-study fashion as though it were a statement of contemporary science?

IMAGE
UNAVAILABLE
FOR
COPYRIGHT
REASONS

It is fair to end with some (abbreviated) conclusions of the author's own:

The evidence from Galileo indicates that science is primarily a method rather than a set of abstract truths; that method involves not the fixed adherence to some formal universal rules, but rather the judicious balancing of such opposites as speculation and observation, quantitative analysis and qualitative considerations. . ; that in particular such judgment does not automatically exclude rhetorical persuasion or aesthetically expressed emotion; but that such exercise of judgment reduces ultimately to a matter of reasoning, namely the drawing of conclusions from premises and the formulation of reasons for claims.

Finocchiaro ends with the admonition that "in order to become, more scientific, the study of reasoning needs a greater empirical orientation towards reasoning as it actually occurs in the world" to be found by employing a "broadly conceived historical approach" not shying away from " attempts at concrete theoretical systematizations".

\title{
Essential techniques in diazotrophy
}

\section{John Postgate}

Methods for Evaluating Biological

Nitrogen Fixation. Edited by F.J. Bergersen. Pp.702. ISBN 0-471-27759-2. (Wiley: 1980.) £38, \$114.

To do justice to a book as important as this in a short review is a frustrating task. It is a compendium of modern methods of studying diazotrophy and, as most readers will know, it is largely new (or improved) techniques which have permitted the spectacular advances of the past few decades.

First, a brief survey of its authors and scope. Dalton describes techniques for the culture of nitrogen-fixing bacteria; Bergersen discusses direct nitrogen analyses (for example Kjeldahl, ${ }^{15} \mathrm{~N}_{2}$ ); Turner and Gibson deal with indirect assays of diazotrophy (acetylene reduction, hydrogen evolution); Gibson copes alone with methods for handling legumes in a laboratory or glasshouse; Bond and Wheeler give details for examining actinorhizal symbioses.

More biochemically, Eady comprehensively surveys methods of extracting, purifying and studying nitrogenase; Appleby and Bergersen deal with leghaemoglobins; Farnden and Robertson attempt, with considerable success, the almost impossible task of deciding what enzymes are metabolically related to nitrogenase, and tell how to handle them - they give priority to plant enzymes. Schwinghamer and Dudman then make a somewhat discursive job of "methods for identifying strains of diazotroph", straying rather often from true practicality and regrettably concerning themselves almost exclusively with rhizobia. In contrast, Cannon's terse chapter on everything you need to know to study the genetics of diazotrophs is a masterly laboratory manual in itself.

Brockwell's wide experience informs his chapter on crop and pasture legumes, which takes the reader out into the field; a comparable authority pervades Thompson's chapter on legume inoculants. Dobereiner describes the relatively new if controversial area of diazotrophic associations involving grasses and grain crops - her account of the much-criticized excised root acetylene assay, as well as other techniques, is useful and balanced. Knowles's chapter on plant communities and soils extends coverage to natural ecosystems; finally, Stewart presents a synoptic view of the cyanobacteria and their associates, detailed and down to earth on the free-living types, less practical on the symbioses.

With such broad coverage some defects are inevitable and I must mention a few. Someone ought to have warned about the hazards of "ghosts", those bacteria which scavenge atmospheric fixed $\mathrm{N}\left(\mathrm{NH}_{3}\right.$ or
$\mathrm{NO}_{\mathrm{x}}$ ) and so simulate diazotrophs, for they are still responsible for occasional false reports of diazotrophy. Bergersen should have mentioned the use of ammonia electrodes, and also warned researchers not to smoke, sweat or permit reagent ammonia in the room (or work near stables!) when doing Kjeldahl analyses. Thompson ought to have warned of the inherent error of Petroff-Hauser chambers (they overestimate). Indeed, enumeration of diazotrophs can be tricky and it is inadequately discussed. Dobereiner considers the enumeration of some, but the topic ought surely to have been in Dalton's brief. Dalton also omitted the important problem of colonial multimorphism in putatively pure strains of rhizobia: $\mathrm{Dr}$ Elkan has shown that they can have different phenotypes and require special detergent media to be seen. Finally, despite its use in California, I question Farnden and Robertson's recommendation of a tritium exchange to assay uptake hydrogenases: tritium uptake is more sensitive and theoretically sounder.

No doubt other criticisms could be made, but they all become trivial in the context of the excellence of the book as a whole. Dr Bergersen is to be congratulated on choosing authors with direct, practical experience of their subjects and ability to communicate that experience to the reader. The information in this book will have a very much longer half-life than that in most of the more theoretical books and the symposia on diazotrophy which are now being published with such regularity. This one is essential for any laboratory teaching or researching in this area and even experienced research workers will benefit from dipping into it.

John Postgate is Professor of Microbiology at the University of Sussex and Director of the Agricultural Research Council's Unit of Nitrogen Fixation.

\section{T-cell controversies}

\section{Werner Haas}

Regulatory $T$ Lymphocytes. Edited by Benvenuto Pernis and Henry J. Vogel. Pp.449. ISBN 0-12-551860-9. (Academic: 1980.) $\$ 47.50, £ 26.50$.

THIS collection of papers and review articles about suppressor $\left(\mathrm{T}_{\mathrm{S}}\right)$ and helper $\left(T_{H}\right) T$ cells was written by a group of experts, mainly from the USA, who met in June 1979 at Columbia University. The majority of findings described are poorly understood and controversial; they will challenge the expert and confuse the nonexpert. 